\title{
SAÚdE COLETIVA NA PERSPECTIVA ECOSSIST ÊMICA: uma possibilidade de ações do enfermeiro
}

M ateus Casanova dos SANT OSa

H edi Crecencia H eckler de SI QU EIRA ${ }^{\text {b }}$

Jose Richard de Sosa SI LVAc

\section{RESUMO}

0 arcabouço da saúde coletiva ao buscar estratégias de proteção ao meio ambiente desenvolve uma prática da consciência ecossistêmica. As práticas ecológicas reconhecem o direito do ser humano de viver em um ambiente saudável e adequado, e a ser infor mado sobre os riscos do ambiente em relação à saúde e seu bem-estar. 0 presente trabalho tem por objetivo tecer uma discussão teórico-reflexiva sobre a adoção das práticas ecológicas urbanas em comunidades e sua relação com a saúde coletiva e vislumbrar possibilidades de inserção das ações do enfermeiro neste espaço. As ações da dial ogicidade, da discussão estimulativa, da aproximação do enfer meiro com o habitat do ser humano, são capazes de encontrar reciprocidade na saúde coletiva e ao enfoque ecossistêmico. 0 respeito as suas crenças e ao seu conhecer em relação as suas necessidades em saúde, pode traduzir-se, objetivamente, na promoção da consciência ecológica e do espírito coletivo voltado para a cidadania.

D escritores: E cossistema. Saúde pública. Fenômenos ecológicos e ambientais. Papel do profissional de enfermagem.

\section{RESUMEN}

E I delineamiento de la salud colectiva al buscar estrategias de protección al medioambiente desarrolla una práctica de la consciencia ecosistémica. L as prácticas ecológicas reconocen el derecho del ser humano de vivir en un ambiente saludable y adecuado, y a ser informado sobre los riesgos del ambiente en relación a la salud y su bienestar. E I presente trabajo tiene por objetivo tejer una discusión teórico-reflexiva sobrela adopción de las prácticas ecológi cas urbanas en comunidades y su relación con la salud colectiva y vislumbrar posibilidades de inserción de las acciones del enfermero en este espacio. L as acciones del diálogo, dela discusión estimulante, dela aproximación del enfermero con el hábitat del ser humano, son capaces de encontrar reciprocidad en la salud col ectiva y al enfoque ecosistémico. E I respeto a sus creencias y a su conocimiento en relación a sus necesidades en salud, puedetraducirse, objetivamente, en la promoción dela consci encia ecológica y del espíritu colectivo vuel to a la ciudadanía.

Descriptores: E cosistema. Salud pública. F enómenos ecológicos y ambientales. R ol de la enfermera.

T ítulo: Salud colectiva en perspectiva ecosistémica: una posi bilidad de la acción de enfermeros.

\section{ABST RACT}

The understructure of the collective heal th as looking for strategies of protection to the envir onment al so develops a practice of ecosystemic conscience T he ecological practices recogniz etheright of thehuman being of living in a healthy and appropriate environment, and being informed about the risks of the environment regarding the health and his welfare. The aim of this present w ork is to stimulate a reflexive theor etically discussion on the adoption of the ecological urbanepractices in communities and the relation with the collective health and to glimpse insertion possibilities of the actions of the nurse in this space. The conversations actions, a stimulative discussion and approximation of the nurse with the habitat of the human, areable to find reciprocity in the collective heal th and to the ecosystemic approach. The respect his bel iefs and to his know ledge in relation his necessities in health, can come across, objectively, in the promotion of the ecological conscience and of the collective wish turned to the citizenship.

D escriptors: E cosystem. P ublic health. E cological and environmental phenomena. N urse's role T itle: Collective health in the ecosystemic per spective: a possibility of actions of the nurse

\footnotetext{
${ }^{a}$ Enfermeiro Especialista em Saúde Coletiva e em Acupuntura e Ele-troacupuntura, M estrando do Programa de Pós-Graduação em Enfermagem da U niversidadeF ederal de Pel otas (U F Pel), D ocente do Curso de E nfermagem da F aculdade Atlântico Sul dePel otas/ A nhanguera E ducacional, Pelotas, Rio Grande do Sul, Brasil.

${ }^{6}$ D outora em E nfermagem, E specialista em M etodologia da Pesquisa e A dministração H ospitalar, D ocente do Programa de Pós-G raduação em Enfermagem da U niversidade Federal do Rio Grande (FURG). Docente do Curso de Enfermagem da Faculdade Atlântico Sul de Pelotas/ A nhanguera E ducacional, M embro Líder do N úcleo de E studo e Pesquisa G erenciamento E cossistêmico em E nfermagem/ Saúde (GEES), Pelotas, Rio Grande do Sul, Brasil.

M estre em Enfermagem, D ocente e Coordenador do Curso de Enfermagem da Faculdade Atlântico Sul de Pelotas/ Anhanguera E ducacional, M embro do Núcleo de Estudo e Pesquisa GEES, Pelotas, Rio Grande do Sul, Brasil.
} 


\section{CONSIDERAÇÕES INICIAIS}

0 ecossistema entendido como comunidade de organismos que interagem entre si e mantém relação com 0 ambiente em que vivem concebe 0 ser humano como elemento integrante dessa comunidade. 0 conjunto de el ementos, estruturantes dessa realidade, ao relacionar-se entre si, é capaz de construir verdadeiras redes no espaço em que co-habita e desenvolver-se de forma harmoniosa e saudável.

Olhando sob essa perspectiva, o ecossistêmico é um conjunto de el ementos interdependentes, integrados, formando o espaço/território/ ambiente(1), lugar onde a rede de relações humanas perpetua a sua cultura pela contínua transferência de matéria e energia entre os seres vivos e o meio.

Seguindo nessa linha de pensamento, entende-se que o ecossistema possui padrões relacionais intrínsecos e extrínsecos. E nquanto os padrões intrínsecos real izam as rel ações com a rede local, formando o seu microssistema, os padrões extrínsecos, se inter-relacionam com outros territórios, trocam, importam e exportam informações e têm como pressupostos os meso e macrossistemas ${ }^{(2)}$. 0 estudo detal hado dos ecossistemas mostra que a maioria das relações entre organismos vivos são essencialmente cooper ativas, car acterizadas pela coexistência e a interdependência, e simbióticas em vários graus ${ }^{(3)}$.

N esse ínterim, salienta-se como ponto provocativo de discussão uma experiência bem sucedida com a adoção de práticas ecológicas urbanas em uma comunidade no município de Porto Alegre, R io G rande do Sul, Brasil( ${ }^{(4)}$. Foi possível perceber nesta comunidade o quanto a saúde coletiva tende a crescer junto ao enfoque ecossistêmico, situação já apreendida em outros trabal hos ${ }^{(5,6)}$.

A preocupação iner ente ao espaço/ territóriocultural mais saudáveis nas comunidades induz às práticas ecológicas urbanas( ${ }^{(4)}$. N essa conjuntura, ag regam-se valores de preser vação e proteção ambiental, percepção do lugar do homem no meio ambiente, desenvolvimento da perspectiva da educação ambiental como uma necessidade da comunidade e ol ho vivo de que o meio ambiente tem estreita relação com questões sociais ${ }^{(4,7)}$. A lém disso, a reflexão ecossistêmica instiga ao uso sustentável do espaço físico e dos recursos naturais, acirra a considerar o destino adequado dos resíduos domés- ticos com separação e reciclagem do lixo visando à diminuição de enfermidades correlacionadas( ${ }^{(4,8)}$, o que significa gerenciar as ações col etivas em busca de um espaço mais saudável. Por conseguinte, existem laços estreitos entre o ger enciamento ecossistêmico, o cuidado com o meio ambiente e a saúde coletiva que de maneira integrada buscam o bem-estar da comunidade, seu espaço/ territóriocultural sustentável.

N este mesmo contexto enquadram-se os princípios de ag roecologia(8-12), plantio de mudas visando à arborização e ampliação da área verde, assim como o cultivo de hortaliças, legumes e plantas medicinais $s^{(4,10,12-14)}$, o que provoca a diminuição de pragas e doenças relacionadas a resíduos putrefeitos, inclusive contribuindo para o espírito de cidadania voltado para a saúde. A lém desses aspectos incluise nesse patamar a questão estética que leva o ser humano a sentir-se mais útil, participativo com 0 seu ambiente. Esses sentimentos, automaticamente, elevam o seu status e com isso, a sua auto-estima e o pertencimento perante o grupo que compõe 0 ambiente ecossistêmico.

As práticas ecológicas urbanas como estratégia em saúde coletiva denotam a importância do trabal ho social a ser desenvolvido em conjunto com a comunidade. N a prática profissional do enfermeiro, através da consulta de enfer magem na atenção básica em saúde, dispõe-se de um espaço adequado para o diagnóstico situacional de cada real idade dos clientes. A visão ecológica e seus princípios, apoiase em ações coletivas, nas trocas entre as pessoas, na alteridade, no convívio, no respeito e no cuidado com a natureza.

Experiências bem sucedidas evidenciam que existem métodos que suscitam idéias inovadoras capazes de modificar o pensar e fazer das pessoas e assim levá-las a uma vida mais saudável(4,14). I sso pode ser facilmente percebido pela fala a seguir, extraída da monografia(14-16) intitulada "Resgatando a integralidade holística nas práticas de cuidado complementar em saúde", projeto aprovado no Comitê de É tica em Pesquisa da Faculdade de M edicina da U niversidade Federal de Pelotas, ofício 009/ 05, em que se entrevistou 21 sujeitos responsáveis em aplicar cuidados complementares em saúde não-convencionais. 0 estudo, observando a Resolução $196 / 96^{(16)}$, foi realizado no município de Pelotas, Rio G rande do Sul, em pontos de referência com práticas de cuidado complementar, alternativo, ecológico e/ ou natural: 
[... ] 0 pensamento novo é de ver o ser humano como um ser completo, conectado: com a realidadeatual, com a condição do planeta, com a sua realidade interior, uma ecologia interior que hoje el e tem que desenvolver, com 0 ambiente e de uma forma afetiva com as pessoas ao seu redor. P or que o planeta está assim? 0 planeta está assim porque 0 ser humano está dissociado da $\mathrm{N}$ atureza. [ ... ] É assim que eu vejo o homem, eleunido à $\mathrm{N}$ atureza, tirando da $\mathrm{N}$ atureza tudo aquilo que ela Ihe oferece com todo o sustento para a sua vida, sua saúdee sua manutenção [ ... ] (entrevista).

A partir desse relato, é possível observar que a teoria ecossistêmica repercute sobremaneira na saúde coletiva e inclusive ambas reforçam a determinação social do processo saúde-doença, o trabaIho em redes e em equipes multiprofissionais ${ }^{(15)}$, a intersetorialidade, a otimização dos recursos em prol da sustentabilidade dos sistemas, a integ ração de saber es entre os sistemas ${ }^{(2)}$, e, a mais notável: a visão de um organismo social e a construção da cidadania(4).

Objetiva-se tecer uma discussão teórico-reflexiva sobre a adoção das práticas ecológicas urbanas em comunidades e sua relação com a saúde coletiva e vislumbrar possibilidades de inserção das ações do enfermeiro neste espaço.

\section{TRILHAS/EST RAT ÉGIAS QUE PODEM SER SEG UIDAS PARA UMA PRÁTICA DA CONSCIÊ NCIA E COSSIST Ê MICA: inclusão do enfermeiro}

A questão ambiental vem influenciando esendo incorporada às discussões da promoção da saúde, integrando as abordagens ecossistêmicas aos problemas de saúde coletiva. Ao discutir o conceito de saúde ecossistêmica, pretende-se incorporar e transcender, numa perspectiva transdisciplinar, difer entes campos de saberes, como a ecologia, a saúde pública, a economia e as ciências sociais e humanas.

Partindo do diagnóstico e da análise da situação ecossistêmica em saúde, e relacionando-o no cenário e no contexto das práticas ecológicas urbanas, é imprescindível destacar algumas dimensões e aspectos que poderão contribuir como estratégias em saúde para o desenvolvimento de comunidades mais saudáveis. $\mathrm{Na}$ comunidade há $\mathrm{O}$ intercâmbio entre a cultura e a natura, construindo redes entre os elementos que compõem essa coletividade ${ }^{(3)}$.
T endo em vista a saúde - como a vida, ela é sempre feita em col etivos. M esmo quando estamos "sós" na experiência do adoecer, estamos intercomunicados com os outros e com o mundo. 0 importante é sentir que, seja como for, fazemos parte ativa de sociedades e culturas e somos, nós próprios, feitos também dessas sociedades e culturas. Essa consciência que resulta do pensar e sentir é uma consciência afetiva, uma consciência crítica, lúdica e sensível de fazer parte.

O fluxo do equilíbrio dinâmico, entre todos os el ementos do ecossistema de uma comunidade, é fator que nutre a rede social local e por isso precisa ser entendida como um bem comum, construído e a ser conservado pelo coletivo. E ssa rede social local forma um organismo próprio e podese dizer que repercute no sistema como um to$\mathrm{do}^{(3,14)}$.

E sse ressoar coletivo gera a consciência ecossistêmica. Entende-se aqui por consciência ecossistêmica a percepção de um homem interligado com o todo que o cerca, a conexão homem-natureza- $\operatorname{cosmos}^{(3,11)}$, desenvolvendo uma consciência coletiva de al teridade, amor ao próximo e de respeito ao homem-natureza ${ }^{(14)}$ junto aos mais variados sistemas que integram e interagem com o todo.

A saúde coletiva como tema da prática de saúde sob distintas perspectivas emerge, através da Reforma Sanitária, no campo teórico-prático brasileiro, repercutindo ideais em saúde que envolvem os indivíduos, as comunidades e os demais grupos de maneira integrada(5) e, porventura, ecossistêmica. E m seu delineamento científico, ela reforça a proteção ao meio ambiente como uma prática da consciência ambiental. As práticas ecológicas urbanas podem tornar-se uma estratégia de ação ambiental, basicamente preventiva e participativa em nível local, que reconhece o direito do ser humano de viver em um ambiente saudável e adequado, e a ser informado sobre os riscos do ambiente em relação à saúde e bem-estar. A o mesmo tempo, define responsabilidades e dever es em relação à proteção, conservação e recuperação do ambiente e da saúde e, sobremodo, desenvolve a educação ambiental através da ampliação da relação homem-natureza, da alimentação saudável e do estímulo aos hábitos saudáveis de vida ${ }^{(4,11,14)}$.

0 homem cidadão percebe em si próprio a integração ao todo. Nesse todo "cidadão" mora a semente da vontade coletiva que al imenta as comunidades e as redes humanas. 0 s princípios de alte- 
ridade e amor entre as pessoas ${ }^{(14)}$ são forças-liga desse tecido conjuntivo social que deve ser sempre renovado de vitalidade e saberes em saúde para se tornar saudável e integrado a um ambiente salutar, onde cultura e natura interagem em harmonia e no qual homem e natureza são um só.

0 enfermeiro em sua práxis profissional se tor na um agente promotor em saúde, podendo tratar a pessoa em sua total idade. D esde a consulta de enfermagem até as atividades de educação em saúde, desenvolvidas na comunidade, a consciência ambiental tem seu espaço garantido. É possível promover o cuidado com o homem-natureza, semeando saber es ecológicos de proteção ambiental nas moradias, nos ambientes de trabalho, na diversidade dos espaços que ocupa. É, igualmente, importante fomentar a responsabilização dos indivíduos, estimular a liderança local nas comunidades para as questões ambientais e dialogar, constantemente, com os usuários dos diferentes espaços para incentivar trocas de experiências de práticas ecológicas urbanas. Essas, possivelmente, operadas através do cultivo de hortaliças e plantas medicinais, reaproveitamento de resíduos domésticos, cuidados com a água e outros bens não renováveis. Além disso, também fazem parte desse processo a higienização do espaço/ território-lugar que ocupa, execução de práticas agroecológicas, adequação na construção das moradias em morros e encostas, reaproveitamento e manutenção do espaço natural em áreas verdes, entre outros. Essas práticas são capazes de auxiliar na proteção ao meio ambiente como uma prática da consciência ambiental.

As ações ecossistêmicas como práticas ecológicas podem estar imbricadas inclusive no trabaIho da equipe de saúde multiprofissional através, por exemplo, da discussão do descarte e do destino adequado dos resíduos das instituições de saúde, do processo de trabalho interdisciplinar em equipe, da relação ecológica entre o profissional de saúde e a comunidade e da relação entre a comunidade e o seu espaço/ ter ritório/ ambiente.

$N$ esse tipo de abordagem profissional, que pode ser realizado pelo enfermeiro nos diferentes espaços que ocupa, observa-se que o espírito de cidadania voltado ao coletivo é, constantemente, retroal imentado com a comunidade, construindo co-responsabilização e consciência ecossistêmica.

\section{CONSIDERAÇÕES FINAIS}

A distinta relação entre o homem e o seu habitat gera repercussões em todo o sistema, pois as interligações são constantes. A adoção de práticas mais saudáveis, que respeitam princípios ecológicos de convivência na natureza, beneficia a vida, a saúde e o equilíbrio dinâmico nos espaços/ territórios/ ambientes habitados pelo homem e do próprio homem como um todo, pois el e é natureza.

0 enfermeiro, ao adotar uma visão ecossistêmica no processo de educação em saúde, no exercício profissional, ao atender o indivíduo em seu todo, tem a oportunidade de progredir nessa relação de bem-estar através da aprendizagem/ ensino para a adoção de práticas ecológicas urbanas, percebendo, em cada momento, o contex to dessa relação com a saúde coletiva.

As práticas ecológicas na saúde coletiva são caminhos potenciais que complementam o fazer saúde e produzem compromissos de ação no mundo capazes de vencer o comodismo, a ociosidade e o sedentarismo dos indivíduos e das coletividades. Inclusive, otimiza os recursos ambientais das comunidades com a valorização da cultura local(4), promoven do a construção da auto-estima, da consciência de cidadania e da saúde comunitária. Ao se estimar o espaço/ ter ritório que se vive, gera-se a força motriz de pertencimento local. I sso atrai os princípios de alteridade e de amor próprio ao ambiente. Esse sentir é um processo salutogênico e ecológico importante que a consciência ecossistêmica fomenta nas práticas ecológicas em saúde coletiva junto aos espaços/territórios/ ambientes.

Esse texto não teve a ambição de esgotar o assunto e as possibilidades que esse tema traz à tona, tanto no próprio modo de viver como também no incremento à prática profissional do enfermeiro. A lém disso, suscita apenas al guns dos pontos convergentes entre a teoria ecossistêmica e a saúde coletiva. A inda há muito que refletir e praticar a respeito dessa inter secção conceitual de saberes. Como desafio, por que não começar? Por que não delinear métodos capazes de contribuir na inserção do enfermeiro nesse espaço e, desta forma, colaborar com a adoção das práticas ecológicas urbanas, tor nando o espaço/ território/ ambiente mais saudável e sustentável?

A o buscar integrar as ciências sociais na compreensão dos problemas ambientais, os enfoques 
ecossistêmicos de saúde, surgem como uma das possibilidades no âmbito da saúde coletiva. Porém, isso não pode ocorrer sem que se mantenha uma perspectiva crítica da sociedade e de suas dinâmicas ger adoras de deg radação ambiental e problemas de saúde, desde a escala local até a escala global.

\section{REFERÊNCIAS}

1 Ribeiro FV. 0 papel do território como estratégia de desenvolvimento de regiões rurais. Campo-T errit. 2007;2(4):38-59.

2 Bronfenbrenner U. A ecologia do desenvolvimento humano: experimentos naturais e planejados. Porto Alegre: Artmed; 1996.

3 Capra F. A teia da vida. São Paulo: Pensamento-Cultrix; 2006.

4 Santos M C, Rossoni E. T ecendo redes na construção de práticas ecológicas urbanas no território de uma unidade básica de saúde. Bol Saúde. 2008;22(1):19-29.

5 Cezar-Vaz M R, Soares M CF, M artins SR, SenaJ, Santos $L R$, Rubira $L T$, et al. Saber ambiental: instrumento interdisciplinar para a produção de saúde. Texto Contexto Enferm. 2005;14(3):391-7.

6 I anni A M Z, Quiterio LAD. Promoção da saúdee meio ambiente no Programa de Saúde da Família: os casos da Barra F unda e Jardim Rio Claro, município de São Paul o. Saúde Soc. 2004;13(1): 81-91.

7 Ferreira Y N . M etrópole sustentável? N ão éuma questão urbana. São Paulo Perspect. 2000;14(4): 139-44.
8 Figueiredo FER. Compostagem de resíduos orgânicos: 0 aproveitamento racional das sobras do dia-adia. Agroecol Hoje. 2002;17:13-14.

9 Baldi VM . Enfermagem e Antroposofia: uma possibilidade de diálogo [ tese] . R ibeirão Preto: U niversidade de São Paulo; 2003.

10 Charity RB. A gricultura orgânica: técnicas e princípios. Agric Biodin. 2002;19(86):22-7.

11 M iklós AAW. De Zaratustra à pedra fundamental da Antroposofia de Rudolf Steiner: agricultura biodinâmica, nutrição e desenvol vimento humano. Agric Biodin. 2004;21(90):36-41.

12 Ávila JC. A visão biodinâmica da compostagem. Agroecol Hoje. 2002;17:22-3.

13 Pauly D. Ciência G oetheanística: um estudo fenomenológico da metamorfose das plantas: parte 3 . Agri Biodin. 2002;19(87):3-5.

14 Santos M C, Heck R M, Lange, C. Resgatando a integ ralidade holística nas práticas de cuidado complementar em saúde [ monografia] . Pelotas: U niversidade Federal de Pelotas; 2005.

15 Ferreira SR, Olschowsky A. Residência integrada em saúde: a inter ação entre as diferentes áreas de conhecimento. Rev Gaúcha Enferm. 2009;30(1):10612.

16 M inistério da Saúde (BR), Consel ho N acional de Saúde, Comitê $\mathrm{N}$ acional de Ética em Pesquisa em Seres H umanos. Resolução 196, de 10 de outubro de 1996: diretrizes e normas regulamentadoras de pesquisa envolvendo seres humanos. Brasília (DF); 1996.

\section{E ndereço do autor / Dirección del autor / Author's address:}

$M$ ateus Casanova dos Santos

Rua D r. Ferreira Soares, 244

96020160, Pelotas, RS

E-mail: mateuscasanova@ig.com.br
Recebido em: 18/ 08/ 2009

A provado em: 11/ 12/ 2009 